ARTICLE

\title{
Management of severe acuite malnutrition
}

\author{
J Cloete, MB ChB, MMed (Paediatrics and Child Health), DCH (SA), Dip HIV Man (SA) \\ Department of Paediatrics and Child Health, Faculty of Health Sciences, University of Pretoria, South Africa
}

Corresponding author: J Cloete (jeane.cloete@up.ac.za)

\begin{abstract}
Malnutrition remains a global health concern and contributes significantly to childhood mortality. Nearly half of all deaths in children $<5$ years of age are attributed to undernutrition, especially in developing countries. It is important to differentiate between acute and chronic malnutrition, as the management and mortality for these two conditions differ. Management should follow integrative management protocols to ensure that mortality and morbidity are minimised. General principles for inpatient management of acute malnutrition can be divided into two phases, i.e. the initial stabilisation phase (usually in the first week) for acute complications, and the much longer rehabilitation phase. The initial phase lasts approximately 1 week and involves intensive monitoring and treatment. Severe acute malnutrition remains a problem in public health, especially in developing countries. Adhering to programmatic approaches for diagnosis and management ensures lower mortality rates and better outcomes.
\end{abstract}

S Afr Med J 2015;105(7):605. DOI:10.7196/SAMJnew.7782

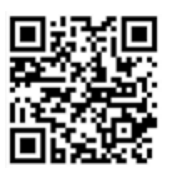

Malnutrition remains a global health concern and contributes significantly to childhood mortality. Nearly half of all deaths in children $<5$ years of age are attributed to undernutrition, especially in developing countries. ${ }^{[1,2]}$ Implementation of programmatic management approaches developed by the World Health Organization (WHO) and United Nations Children's Fund (UNICEF) has markedly reduced fatalities due to severe acute malnutrition (SAM). Further expansion of the existing programmes to include community-based initiation of treatment should decrease the mortality even further. This has been documented in numerous studies as being successful in rural regions of Africa and Asia. ${ }^{[1,3-7]}$

Acute malnutrition develops when undernutrition occurs in an essential period of childhood growth, and is exacerbated by coexistent infection and metabolic abnormalities.

\section{Diagnosis}

It is important to differentiate between acute and chronic malnutrition, as management and mortality of these two conditions differ. ${ }^{[3,6]}$ The hallmark of chronic malnutrition is stunted growth, while in acute malnutrition there is wasting, with or without the presence of symmetrical bilateral pitting oedema and other signs, such as sparse hair, skin changes or an enlarged smooth liver. Patients with chronic malnutrition occasionally develop acute malnutrition owing to the presence of infection or a sudden change in food security. SAM in children aged 6 months - 5 years can be divided into three groups, as shown in Fig. 1. Marasmic patients have signs of wasting in the axilla, groin and buttock areas, and subsequently on the face. Kwashiorkor is mainly diagnosed by the presence of bilateral symmetrical pitting oedema (the degree should be graded for severity). These patients often have additional signs, such as hyperpigmented dermatosis that may desquamate, which in turn may become secondarily infected. It is important to consider other possible diagnoses in patients who demonstrate a poor response to treatment or may have additional conditions. Children with marasmic kwashiorkor are often severely ill and have a higher risk of mortality.

Management of the three categories of acute malnutrition should be approached in the same manner by following integrative management protocols to ensure that mortality and morbidity are kept as low as possible. ${ }^{[3,4,6,8,9]}$

\section{Treatment}

Every patient with SAM should be assessed to decide whether in- or outpatient management is best. In developing countries, with the highest incidence of undernutrition, lack of resources limits the ability to admit every child. Effective screening to correctly enrol patients in outpatient programmes has been shown to improve survival. ${ }^{[3-7,10-14]}$ Classifying patients according to anthropometry, presence or absence of symmetrical bilateral pitting

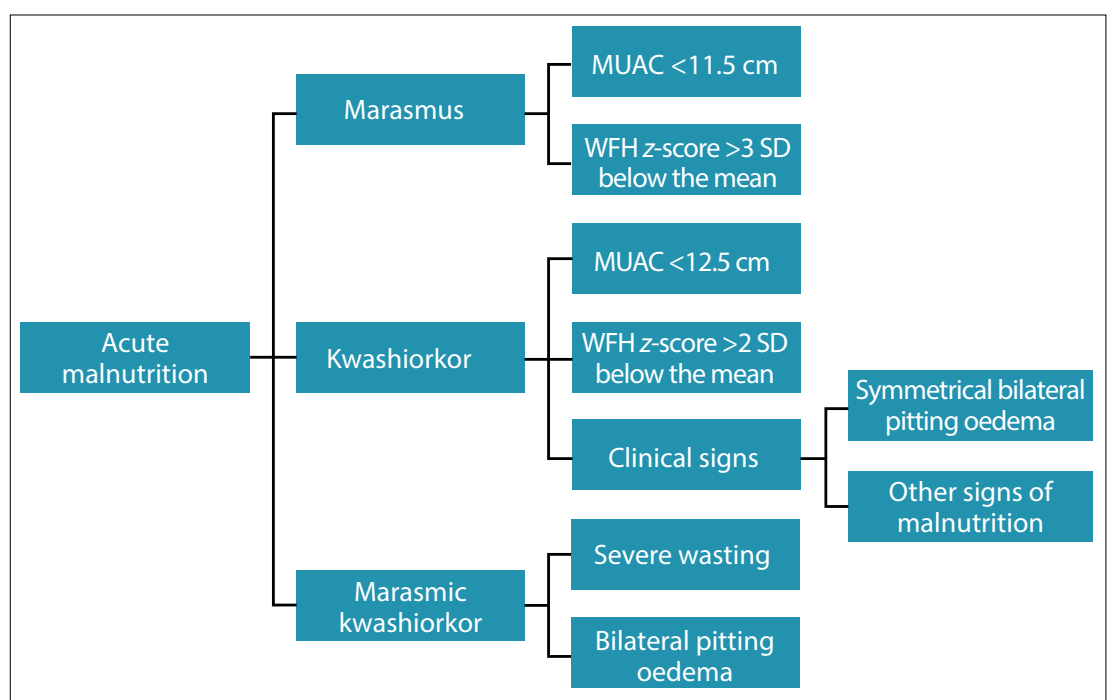

Fig. 1. Clinical forms of acute malnutrition $(M U A C=$ mid-upper-arm circumference; $W F H=$ weight for height; $S D=$ standard deviation). 


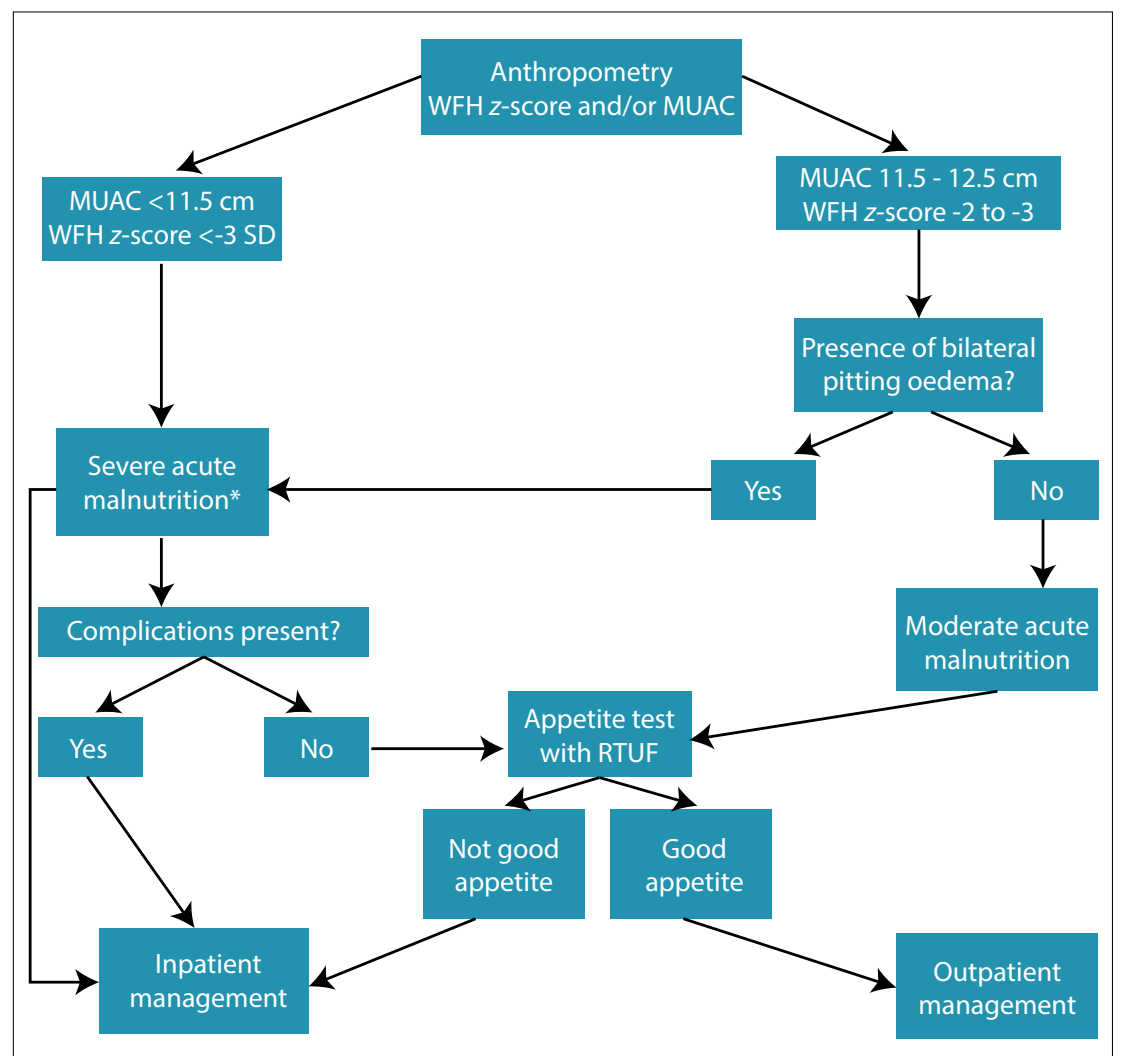

Fig. 2. In- or outpatient management for severe acute or moderate acute malnutrition (RTUF = readyto-use therapeutic food). ${ }^{\star}$ Severe acute malnutrition can be treated on an inpatient basis, irrespective of complications, especially in the presence of oedema.

oedema and complications (pneumonia, sepsis, severe diarrhoea with shock and metabolic complications, i.e. hypoglycaemia and hypothermia) assists with decisionmaking with regard to in- or outpatient management (Fig. 2). ${ }^{[2,3,8,9,15-18]}$

The beneficial principles for inpatient management of acute malnutrition can be divided into two phases, i.e. the initial stabilisation phase (usually in the first week, when acute complications are managed) and a much longer rehabilitation phase (Table 1).

Table 1 reflects the general approach to the inpatient management of SAM (WHO 10-step approach).

\section{Stabilisation phase}

Prevention and treatment of hypoglycaemia It is of the utmost importance to monitor glucose levels in patients with SAM; their blood glucose should be assessed on admission. Ongoing glucose evaluation is important, especially when hypothermia is present. If facilities are not available for sideroom or laboratory investigation of blood glucose, patients should be treated as though hypoglycaemia is present. Regular feeding must be continued over a 24-hour period (not interrupted at night) as an important preventive measure for hypoglycaemia. If it is present, the patient should be actively managed, preferably with oral feeds or fluids, as mortality can thus be prevented. ${ }^{[4,9]}$

\section{Prevention and treatment of hypothermia} As hypothermia is associated with mortality, it is important to monitor body temperature on admission and during rewarming. This should occur 2-hourly until the child's temperature remains $>36.5^{\circ} \mathrm{C}$. Prevention of hypothermia, by ensuring that the patient is covered at all times and kept away from draughts, and avoiding prolonged exposure during bathing and medical examination, is critical. Wet nappies, clothes and bedding must be changed quickly and it is important to check blood glucose levels during episodes of hypothermia. The patient should be fed immediately or rehydration should be commenced as needed. Rewarm children with a warmed blanket and place a heater or lamp nearby. To rewarm infants, they must be placed on their mother's bare chest. $^{[2]}$

\section{Treatment of dehydration and diarrhoea}

Assessment of dehydration in severely malnourished children in the presence of oedema may be challenging. Small
Table 1. General approach to inpatient management of severe acute malnutrition (World Health Organization 10-step approach)

Stabilisation phase

- Prevention and treatment of hypoglycaemia

- Prevention and treatment of hypothermia

- Prevention and treatment of dehydration

- Correction of electrolyte imbalance

- Treatment of infection

- Correction of micronutrient deficiencies

- Feeding

Rehabilitation phase

- Continued feeding

- Achieve catch-up growth

- Provide sensory stimulation and emotional support

- Preparation for discharge

volumes of unformed stools may be passed as a consequence of the underlying malnutrition; this should not be confused with profuse watery diarrhoea. To prevent dehydration when a child has continuing watery diarrhoea, breastfeeding or starter formula feeding should be encouraged. Stool losses should be replaced with approximate volumes of oral rehydration solution, which is much safer than intravenous fluids. ${ }^{[3,4,7,8,10,11,19-21]}$

All children with profuse watery diarrhoea should be assumed to be dehydrated and managed with rehydration measures. These patients have low cardiac reserves - intravenous fluids may lead to volume overload and possibly cardiac failure. Oral rehydration is a much safer option for correction of dehydration. Shock from dehydration and sepsis are also likely to coexist in severely malnourished children. Overhydration and repeated intravenous boluses during resuscitation increase mortality. The amount of fluid administered is determined by the child's response and monitored by pulse and respiratory rates. With improvement in these rates, intravenous fluid boluses should be discontinued. Intravenous fluids (halfstrength Darrow's solution with 5\% dextrose) should be administered at a conservative rate, rehydrating slowly, or alternatively oral or nasogastric rehydration with an oral rehydration solution should be employed. It is imperative to frequently re-evaluate the patient to ensure that overhydration does not occur, which is a frequent cause of death. Continued rapid breathing and a rapid 
pulse during rehydration suggest coexisting infection or overhydration. The following are signs of excess fluid (overhydration): increased respiratory and pulse rates, increased oedema and puffy eyelids. In these instances, fluids must be discontinued immediately. ${ }^{[3,4,7,8,10,11,19,20]}$

Additional treatment modalities for diarrhoea include the use of zinc supplementation. This has been shown to be beneficial, shortening the duration of the illness. In dysentery, the administration of intravenous cefotaxime or ceftriaxone must be considered. ${ }^{[3,8,18-20,22-24]}$

\section{Correction of electrolyte imbalances}

All severely malnourished children have excess body sodium, even though plasma sodium may be low. Fluids, or feeds containing excessive sodium, may cause mortality. Potassium and magnesium deficiencies are also present and may take at least 2 weeks to correct (Box 1). Oedema is partly due to these imbalances and is consequently not treated with a diuretic.

\section{Treatment of infection}

In severe malnutrition the usual signs of infection, such as fever, are often absent, and infections are often occult. Therefore, broad-spectrum antibiotics with adequate Gram-positive and -negative cover should be provided. Where specific infections are identified, specific antimicrobials should be administered, e.g. antimalarial treatment for malaria and metronidazole for gastrointestinal infections and infestations. ${ }^{[7,8,19,25]}$

Box 1. Dosage of potassium chloride and magnesium supplementation

Potassium chloride solution 25 - $50 \mathrm{mg} / \mathrm{kg} / \mathrm{dose}$ orally 3 times daily until oedema subsides:

$<10 \mathrm{~kg}-250 \mathrm{mg}$

$>10 \mathrm{~kg}-500 \mathrm{mg}$

Extra magnesium: $0.4-0.6 \mathrm{mmol} / \mathrm{kg} /$ day
Correction of micronutrient deficiencies

Vitamin and mineral deficiencies are common in malnutrition. Supplementation (Table 2) should be given for at least 2 weeks. Although anaemia is frequently present, iron supplementation should not be commenced initially, but delayed until the child has a good appetite and starts gaining weight - usually by the second week. Early iron supplementation may aggravate infection status.

\section{Start cautious feeding}

Feeding a malnourished child takes place in two phases. During the stabilisation phase a cautious approach is required because of the child's compromised physiological state and reduced homeostatic capacity. Feeding should start as soon as possible, but in small volumes. Starting with feeds that are too large places the child at greater risk of developing the 'refeeding syndrome'. A starter formula of $\sim 75 \mathrm{kcal} / 100 \mathrm{~mL}$ and $0.9 \mathrm{~g}$ protein/100 mL should, ideally, be initiated. The child should be weighed daily and it is useful to monitor the amount of feed remaining after a meal and the frequency and consistency of stools. These should diminish progressively. Signs of progression to the rehabilitation phase include a return of appetite and a loss of all oedema, which usually occurs about 1 week after admission. A gradual transition to the rehabilitation phase is recommended to avoid the risk of heart failure, which may occur if malnourished children suddenly consume large-volume feeds.

\section{Rehabilitation phase}

In the rehabilitation phase, a vigorous approach to feeding is required to achieve high intakes and rapid weight gain of $10 \mathrm{~g} / \mathrm{kg} /$ day. Ready-to-use therapeutic food (RTUF) packages have been successful, not only during outpatient management programmes, but also during the rehabilitation phase. An alternative option is a higher energy and protein-containing formula, such as the $\mathrm{WHO}$

Table 2. Micronutrient and vitamin replacements

\begin{tabular}{ll}
\hline Micronutrient or vitamin & Dosage \\
\hline $\begin{array}{l}\text { Vitamin A } \\
\text { - Orally on day 1, unless there is definite evidence } \\
\text { that a dose has been given in the last month }\end{array}$ & $6-12$ months: $50000 \mathrm{IU}$ \\
$\begin{array}{l}\text { Multivitamin supplement } 100000 \mathrm{IU} \\
\text { - Give daily for at least } 2 \text { weeks }\end{array}$ & \\
Folic acid & $12 \mathrm{months:} 200000 \mathrm{IU}$ \\
Zinc & $2 \mathrm{mg} / \mathrm{kg} /$ day \\
Copper & $0.3 \mathrm{mg} / \mathrm{kg} /$ day \\
Iron & $3 \mathrm{mg} / \mathrm{kg} /$ day, but only when gaining weight
\end{tabular}

F-100 formula. Continued monitoring after transition would include weight assessment every morning. If weight gain is poor, the patient would benefit from a full nutritional assessment; otherwise an alternative diagnosis should be considered..$^{[4,8,15,17,26]}$

Provide sensory stimulation, emotional support and follow-up after recovery

In severe malnutrition, there is delayed mental and behavioural development. A cheerful and stimulating environment should be provided for the patient, with provision of structured play therapy for 30 minutes per day as soon as the child is well enough to be active. Maternal involvement, where possible, is important and an essential education contact point before discharge to ensure continued stimulating play at home. Discharge should occur with a clear follow-up plan, including frequent weight assessment. Furthermore, ensure that booster immunisations and vitamin $\mathrm{A}$ are given. ${ }^{[21]}$

\section{Conclusion}

SAM remains a problem in public health, especially in developing countries. Adhering to programmatic approaches for diagnosis and management ensures lower mortality rates and better outcomes.

\section{References}

1. Blo M, Borghi E, Frongillo E, Morris R. Underweight in 1990 and 2005. J Am Med Assoc 2004;291:2600-2606.

. World Health Organization (WHO) and United Nation Children's Fund (UNICEF). WHO Child Growth Standards and the Identification of Severe Acute Malnutrition in Infants and Children Geneva: WHO, 2009

3. Collins S. Dent N Binn P et al Management of severe acute malnutrition in children. Lancet 2006;368:1992-2000. 4. Trehan I, Manary MJ. Management of severe acute malnutrition in low-income and middle-income countries.
Arch Dis Child 2014;100:283-287. [http://dx.doi.org/10.1136 archdischild-2014-306026

5ouam CE, Delisle H, Ebbing HJ, et al. Perspectives fo integration into the local health system of community-based management of acute malnutrition in children under 5 years: A qualitative study in Bangladesh. Nutr J 2014;13:1-15. [http:// dx.doi.org/10.1186/1475-2891-13-22]

6. Collins S. Treating severe acute malnutrition seriously. Arch Dis Child 2007;92:453-461.

Bhan MK Bhandari N, Bahl R. Management of the severely malnourished child: Perspective from developing countries. BMI 2003;326:146-151.

8. WHO. Guideline: Update on the management of severe acute malnutrition in infants and children. 2013. www.who.int/ malnutrition in infants and children. 2013. Www.who.int/
entity/maternal_child_adolescent/documents/severe-acuteentity/maternal_child_adolescent/doc

9. WHO. Management of severe malnutrition: A manual fo physicians and other senior health workers. www.who.int/entity/ nutrition/publications/guidelines/updates_management_SAM infantandchildren/en/ (accessed 15 April 2015).

10. Ashworth A, Chopra M, McCoy D, et al. WHO guidelines for management of severe malnutrition in rural South African hospitals: Effect on case fatality and the influence of operational factors. Lancet 2004;363:1110-1115.

11. Bernal C, Velásquez C, Alcaraz G, Botero, J. Treatment of severe malnutrition in children: Experience in implementing the World Heath Org intion Health Organization guidelines in Turbo, Colombia. J Pedia Gastroenterol Nutr 2008:633

12. Chinkhumba J, Tomkins A, Banda T, Mkangama C, Ferguson P. The impact of HIV on mortality during in-patient rehabilitation of severely malnourished children in Malawi. Trans R So Trop Med Hyg 2008;102:639-644. [http://dx.doi.org/10.1016/j. trstmh.2008.04.028]

13. UNICEF. Improving child nutrition. The achievable imperative for global progress. 2013. www.unicef.org/nutrition/index_68661. html (accessed 15 April 2015). 
14. Norman K, Pichard C, Lochs H, Pirlich M. Prognostic impact of disease-related malnutrition. Clin Nutr 2008;27:5-15

15. Prudhon C, Briend A, Prinzo Z, et al. WHO, UNICEF and SCN informal consultation on communitybased managment of severe acute malnutrition in children. Food Nutr Bull 2006;27(3 Suppl):S99-S104 16. De Onis M, Onyango AW, Borghi E, Garza C, Yang H. Comparison of the World Health Organization (WHO) Child Growth Standards and the National Center for Health Statistics/ WHO international growth reference: Implications for child health programmes. Public Healt Nutr 2006;9:942-947.

17. Hendricks M, Bourne L. An integrated approach to malnutrition in childhood. S Afr Gauge 2010;2:46-52 8. Iannotti LL, Trehan I, Clitheroe KL, Manary MJ. Diagnosis and treatment of severely malnourished children with diarrhoea. J Paediatr Child Health 2014;51:387-395. [http://dx.doi.org/10.1111/jpc.12711]

19. Amadi B, Kelly P, Mwiya M, et al. Intestinal and systemic infection, HIV, and mortality in Zambian children with persistent diarrhea and malnutrition. J Pediatr Gastroenterol Nutr 2001;32:550-554.

20. Bhutta ZA, Bird S, Black R, et al. Therapeutic effects of oral zinc in acute and persistent diarrhea in childre in developing countries: Pooled analysis of randomized controlled trials. Am J Clin Nutr 2000;72:1516-1522.
21. Ashworth A, Khanum S, Jackson A, Schofield C. WHO Guidelines for the inpatient treatment of severely malnourished children. 2003. www.who.int/entity/nutrition/publications/severemalnutrition/9241546093/ (accessed 15 January 2015).

22. Bahl R. Bhandari N, Saksena M, et al. Efficacy of zinc-fortified oral rehydration solution in 6- to 35-month-old children with acute diarrhea. J Pediatr 2002;141:677-682.

23. Bhatnagar S, Bahl R, Sharma P, et al. Zinc with oral rehydration therapy reduces stool output and duration of diarrhea in hospitalized children: A randomized controlled trial. J Pediatr Gastroenterol Nutr 2004;38:34-40.

24. Kerac M, Bunn J, Seal A, et al. Probiotics and prebiotics for severe acute malnutrition (PRONUT study): A double-blind efficacy randomised controlled trial in Malawi. Lancet 2009;374:136-144. (http://dx.doi.org/10.1016/S0140-6736(09)60884-9]

25. Trehan I, Goldbach H, LaGrone L, et al. Antibiotics as part of the management of severe acute malnutrition. N Engl J Med 2013;368:425-435. [http://dx.doi.org/10.1056/NEJMoa1202851]

26. Lenicek Krleza J, Misak Z, Jadresin O, Skaric I. Refeeding syndrome in children with different clinical aetiology. Eur J Clin Nutr 2013;67:883-886. [http://dx.doi.org/10.1038/ejcn.2013.58] 